\title{
Dapsone-resistant Leprosy and Its Implications for Leprosy Control Programmes
}

\author{
J. M. H. PEARSON*, J. A. CAP, G. S. HAILE \\ Medical Research Council Leprosy Project, \\ National Leprosy Control Project and \\ All Africa Leprosy and Rehabilitation Training Centre (ALERT), \\ Addis Ababa, Ethiopia \\ and \\ R. J. W. REES \\ National Institute for Medical Research, \\ London NW7 1AA, England
}

\begin{abstract}
The incidence of suspected dapsone-resistant leprosy in the Addis Ababa area is now about 3\% per annum of all lepromatous patients under treatment, and this figure may not be atypical of other areas of the world. New (and expensive) treatment programmes are needed to prevent the emergence of dapsone-resistant leprosy; and training programmes and administration of leprosy control programmes need revision to make possible the early diagnosis and correct management of dapsone-resistant cases. This paper suggests some ways in which the problems of diagnosis, treatment and prevention of dapsone-resistant leprosy can be tackled under field conditions. If measures of this type are not undertaken, there is serious risk that the spread of primary dapsone-resistant leprosy will make leprosy control by chemotherapy unattainable.
\end{abstract}

\section{Introduction}

Patients who have developed dapsone-resistant leprosy are now being diagnosed in increasing numbers, and are indeed becoming one of the major sources of anxiety in the management of leprosy control programmes. Even one patient with progressive disease despite regular treatment will lower the morale of a whole clinic, encourage the belief that leprosy is indeed incurable, and so make case holding more difficult. Also there is an obvious risk that such patients could be a source of new leprosy cases which will be dapsone-resistant from the start. Prompt identification of patients with prima facie evidence of dapsone resistance, facilities for proper investigation and management, and availability of second line drugs for treatment of resistant cases are therefore now essential parts of a leprosy control programme.

* Requests for reprints should be addressed to J. M. H. P. at the National Institute for Medical Research, London NW7 1AA, England.

Received for publication 19 February, 1977. 
These requirements in themselves, however, are insufficient. Properly implemented, they will deal with new cases of dapsone-resistant leprosy as they arise; but prevention is better than cure. The application to leprosy of the principles of prevention of drug resistance which have been established in the field of tuberculosis is long overdue, and treatment policies for leprosy control programmes need revision with this end in view. Furthermore, the possible presence of cases of primary dapsone resistance may require investigation: should it prove to be a significant problem in any particular area, treatment regimens will need yet further modification.

These innovations will affect both patient care and also many aspects of training, supervision and administration. (It is possible that this is one reason for hesitation over their introduction.) The purpose of this paper is to review the findings of dapsone-resistant leprosy in Ethiopia, where it has been possible to study the problem more fully than in most centres, and where there is greater awareness of its extent and potential dangers, and suggest some principles which can be applied to the diagnosis, treatment and prevention of dapsone resistance in leprosy control programmes.

\section{Findings in Ethiopia}

Dapsone therapy was introduced to Ethiopia during the early 1950s, and the first patients with clinical evidence of dapsone-resistant leprosy were seen during the period 1965-1970. By the end of 1972, 41 patients had shown sufficiently clear evidence of clinical deterioration despite continued and reasonably supervised dapsone therapy to require transfer to treatment with another drug. At that time mouse foot-pad tests could only occasionally be undertaken; the clinical diagnosis was, however, confirmed in all 4 cases in which they were performed.

From 1973 onwards patients with clinical evidence of dapsone-resistant leprosy have been seen in increasing numbers in both city and rural clinics, though they have been very uncommon in clinics established for shorter periods than about 10 years. It is not possible to give accurate figures for the country as a whole; facilities for diagnosis are not fully developed, and not all suspected cases are referred to the central leprosy hospital in Addis Ababa. However, from a total in 1976 of about 65,000 registered patients (about a quarter of them lepromatousLL or BL) about 350 have been reviewed in Addis Ababa for suspected dapsone resistance. Results of mouse foot-pad tests were available in only 82 cases, but only in 4 of them was the clinical suspicion disproved. It appears, therefore, that when, on sympathetic questioning, these patients stated that their disease was getting worse in spite of continued and reasonably regular treatment with dapsone, they were usually telling the truth.

In Addis Ababa itself the problem of dapsone-resistant leprosy can be more accurately defined. Since early 1973 all patients receiving treatment in Addis Ababa and suspected of developing dapsone-resistant leprosy have been referred to a single unit, the Medical Research Council Leprosy Project, for investigation and management. The figures of this group of patients are therefore more complete and more susceptible to analysis.

During the 4 years 1973-76 the number of registered patients attending clinics in Addis Ababa and classified as lepromatous has remained fairly stable at about 1500. From this population 50-60 patients per annum have shown evidence of 
dapsone-resistant leprosy (Table 1). Thus the incidence of suspected cases in these clinics is about $3 \%$ per annum.

The results of mouse foot-pad tests, in patients in Addis Ababa and those from elsewhere in Ethiopia, are shown in Table 2. (About $60 \%$ of the tests were performed in Ethiopia, the remainder in the National Institute for Medical Research, London. Duplicate tests demonstrated good agreement between the results from the 2 laboratories.) Patients changing treatment without trial were those whose leprosy was sufficiently severe (i.e. damaging eyes, larynx, testes or nerves) as to make the risk of further deterioration unjustifiable. Such patients were given priority for mouse foot-pad tests which, when performed, always showed dapsone resistance. The other group of patients receiving priority were those from outside Addis Ababa. For patients living in Addis Ababa, who could be more fully supervised, reliance was chiefly placed on the results of a period of trial treatment with dapsone.

\section{TABLE 1}

Number of patients in the Addis Ababa area with suspected dapsone-resistant leprosy

\begin{tabular}{ccc}
\hline Year & \multicolumn{2}{c}{$\begin{array}{c}\text { Number of patients } \\
\text { Now cases }\end{array}$} \\
\hline 1972 & & 41 \\
1973 & 56 & 97 \\
1974 & 63 & 160 \\
1975 & 53 & 213 \\
1976 & 63 & 276 \\
\hline
\end{tabular}

TABLE 2

Results of mouse foot-pad dapsone sensitivity tests according to clinical status of 361 patients with suspected or proven dapsone-resistant leprosy

\begin{tabular}{|c|c|c|c|c|}
\hline \multirow[t]{2}{*}{ Clinical status } & \multicolumn{4}{|c|}{$\begin{array}{l}\text { Number of patients } \\
\text { Mouse foot-pad tests performed }\end{array}$} \\
\hline & $\begin{array}{l}\text { Dapsone } \\
\text { resistant }\end{array}$ & $\begin{array}{l}\text { Dapsone } \\
\text { sensitive }\end{array}$ & $\begin{array}{l}\text { Results } \\
\text { awaited }\end{array}$ & $\begin{array}{l}\text { Not } \\
\text { tested }\end{array}$ \\
\hline \multicolumn{5}{|l|}{ Patients in Addis Ababa } \\
\hline $\begin{array}{l}\text { Changed treat ment without } \\
\text { trial }\end{array}$ & 40 & 0 & 1 & 61 \\
\hline $\begin{array}{l}\text { Changed treatment having } \\
\text { deteriorated during trial }\end{array}$ & 9 & 1 & 2 & 27 \\
\hline Still under trial & 9 & 1 & 2 & 147 \\
\hline \multicolumn{5}{|l|}{ Patients elsewhere in Ethiopia } \\
\hline trial & 4 & 0 & 2 & 8 \\
\hline $\begin{array}{l}\text { Changed treatment having } \\
\text { deteriorated during trial }\end{array}$ & 2 & 0 & 1 & 2 \\
\hline Still under trial & 14 & 2 & 3 & 23 \\
\hline
\end{tabular}


With such large numbers of patients with acquired dapsone resistance the risk of primary dapsone-resistant leprosy is obvious. A small scale study including patients from Addis Ababa and other areas where dapsone has been in use for 10 years or more has shown that of 8 patients with previously untreated lepromatous leprosy, 5 have shown dapsone resistance on mouse foot-pad testing (Pearson, Haile and Rees, 1977).

\section{Discussion}

To understand some of the problems of diagnosing dapsone resistance in leprosy, and to clarify the reason for the "lag phase" of almost a quarter of a century from the first use of dapsone to the appreciation of how potentially serious a problem dapsone resistance can be, it is necessary to review some of the properties of dapsone, and to define "dapsone resistance" as precisely as possible.

\section{THE PROPERTIES OF DAPSONE}

The most striking property of dapsone is its extreme effectiveness in inhibiting the multiplication of Mycobacterium leprae. Evidence both from experimental leprosy in the mouse and small scale clinical trial (Waters et al., 1968) indicates that dapsone in a dosage as low as $1 \mathrm{mg}$ daily will (at least initially) control the infection and lead to the death of the majority of leprosy bacilli in the patient. On the other hand, dosage levels of $100 \mathrm{mg}$ daily are normally safe and free of toxicity, and even higher dosage can be used on occasion with few side effects. Thus the ratio of achieved to minimal inhibitory concentration in patients receiving dapsone in full dosage is unusually high for the chemotherapy of any infection; certainly it is much higher than that achieved by any drug used in the chemotherapy of tuberculosis.

It is this remarkable "safety margin" which accounts for the good results of dapsone used as monotherapy even in lepromatous leprosy. Other drugs are effective against leprosy, but their use as monotherapy against lepromatous leprosy almost always leads to the emergence of acquired drug resistance, usually within the first 3 years of treatment (Garrod and Ellard, 1968; Hastings et al., 1969). These other drugs have "safety margins" against leprosy comparable to those of drugs used in the chemotherapy of tuberculosis. The multiplication times of $M$. tuberculosis and M. leprae are different, but clinical evidence of drug resistance takes approximately the same number of generation times to emerge. It is also this "safety margin", together with the long multiplication time of $M$. leprae, which accounts for the prolonged delay in the appearance of cases of dapsone-resistant leprosy. The first proven cases were reported by Pettit and Rees (1964), and it was more than a decade later that the extent of the problem in Ethiopia was analysed.

\section{THE DEFINITION OF DAPSONE RESISTANCE}

The remarkable sensitivity of $M$. leprae to dapsone was established by use of foot-pad sensitivity tests (Shepard et al., 1969). It was shown that all strains obtained from previously untreated patients were inhibited from multiplying in the mouse foot-pad when mice were fed $0.0001 \%$ dapsone in the diet. Leprosy is therefore defined as dapsone-resistant when bacilli obtained from a patient multiply in mice receiving dapsone $0.0001 \%$ in the diet.

However, when patients showing clinical evidence of dapsone resistance began 
to be observed, and strains of $M$. leprae from these patients were set up for drug sensitivity tests, it was shown that the degree of resistance could vary remarkably in different patients. Thus, strains of $M$. leprae have been isolated which multiply in the presence of $0.0001 \% 0.001 \%, 0.01 \%, 0.025 \%$ and even $0.1 \%$ dapsone (Pearson et al., 1975; Pettit and Rees, 1964). The dapsone dosage in man equivalent to these levels in mice is shown in Table 3.

TABLE 3

Dapsone dosage in mouse diet and human therapy required to give similar blood dapsone levels

Dapsone concentration in mouse diet
Dapsone dosage required

to give comparable

blood levels in man
$0.0001 \%$
$0.001 \%$
$1 \mathrm{mg}$ daily
$10 \mathrm{mg}$ daily
$0.01 \%$
$0.1 \%$
$100 \mathrm{mg}$ daily
$1 \mathrm{~g}$ daily

The implication of these findings is that dapsone resistance develops in a "stepwise" fasion rather than in a single step mutation. This complicates the clinical diagnosis of dapsone-resistant leprosy. For instance, some patients harbour bacilli which multiply in mice fed $0.0001 \%$ dapsone in the diet, but are inhibited at $0.001 \%$. The latter concentration represents human dosage of about $10 \mathrm{mg}$ daily. Such patients therefore could be expected to improve (and indeed do improve) at least for a period when treated with dapsone in maximal dosage; it is just possible that some of these patients might be curable with dapsone alone. However, such patients, when treated with dapsone in full dosage, improve for 1-4 years and then almost without exception deteriorate yet again; at this stage their bacilli have been shown to possess a higher degree of dapsone resistance. Thus dapsone monotherapy leads to further selective multiplication of the higher resistant mutants of $M$. leprae; the initial improvement due to higher or more regular dosage can, however, mislead a physician into thinking that the infection is not dapsone resistant.

\section{THE DIAGNOSIS OF DAPSONE-RESISTANT LEPROSY}

\section{History}

As in the case of other infections, the history of dapsone resistance is that, after initial clinical improvement there is recrudescence and progress of the disease even despite continued therapy. In the case of leprosy, however, the multiplication time of $M$. leprae is long and so the period till relapse is long. Thus, staphylococcal infections show streptomycin resistance within a few days, and streptomycin-resistant tuberculosis requires a few months to emerge. Streptomycin resistance in leprosy, however, requires several years to develop (Hastings et al., 1969) and dapsone-resistant leprosy may emerge after 20 years or more of regular treatment (Pearson et al., 1975).

\section{Clinical features}

The clinical features of acquired dapsone-resistant leprosy are characteristic. Patients are always suffering from lepromatous leprosy, and show a mixture of 
old and new lesions. There is evidence (such as wrinkled ear lobes, and resolved nodules and plaques) of regressing leprosy. But there are also newly appeared, active nodules. These nodules often appear at unusual sites, such as the eye, abdomen, and antecubital and popliteal fossae. Skin smears taken from the active new lesions show high bacteriological and morphological indices (BI and MI). If, however, skin smears are taken from "routine" sites (such as the ear lobes) in these cases, both $\mathrm{BI}$ and MI are likely to be low. Biopsies from active lesions will show active leprosy; occasionally the clinical appearance and histological classification of the lesions in the very early stages are borderline rather than lepromatous.

\section{The demonstration of dapsone resistance under field conditions}

It is possible to define 3 stages which lead from suspicion to certainty of dapsone-resistant leprosy.

(a) The patient says he is taking treatment but that he is developing new lesions.

- (b) On examination he has lesions that appear to be those of active lepromatous leprosy, and skin smears show a high BI and MI in these lesions, though they remain low elsewhere. The suspicion is enhanced if the lesions are in "unusual" sites.

(c) When the patient receives more closely supervised treatment with dapsone, he does not obtain lasting improvement. If it is certain that the patient's disease is failing to respond, and also certain that he is taking dapsone reasonably regularly, then the leprosy must be dapsone-resistant.

Proof of dapsone resistance depends therefore on confirmation (by means of a supervised clinical trial) of 2 points.

- (a) The patient's disease is progressing. (In practice, this means distinguishing between active leprosy and reactions.)

For this, the most satisfactory method is the "old fashioned" clinical drawing, recording the leprosy lesions on body charts. These drawings have proved as accurate and useful as photographs, and are reasonably reliable even when sequential assessments are done by different workers. They are not hard to draw, as all that is needed is a record of the position, number and size of the lesions. Drawings are cheaper than photographs, and as reliable (except when first class colour pictures under identical conditions can be obtained over a period of months or years).

It is essential that the clinical assessment of progress or deterioration should be confirmed by good quality skin smears, well taken, well stained, and the BI and MI accurately determined. The smears should be taken from both ear lobes (representing "old" lesions) and from 4 other active skin lesions. It is not necessary for serial smears to be taken from the same sites; indeed, there are advantages in selecting the most active-looking lesions on each occasion.

This part of the diagnosis of dapsone resistance demands no more facilities than those which should be normally available in a leprosy control service.

* (b) The patient is taking dapsone regularly. In practice, this means treatment that is as fully supervised as possible, ideally with dapsone given by injection (proof of intake) or monitoring dapsone excretion in the urine (proof of absorption of swallowed tablets). This aspect of the clinical trial is somewhat more demanding. Our priority in Ethiopia has been to encourage regular drug 
taking (though we can also monitor the urine for the presence of dapsone). In addition to personal contact and encouragement, we have employed 2 methods of encouragement.

(1) For patients living close to clinics with facilities for injections, we have encouraged attendance for weekly injections of dapsone, each injection being recorded. The dosage (400 $\mathrm{mg}$ weekly) is adequate for a trial of this type.

(2) Patients who cannot attend clinics weekly are prescribed a dapsone tablet differing from the usual one in appearance. The one we use is a standard $100 \mathrm{mg}$ tablet, sugar coated by a local manufacturer. This process is inexpensive.

Both methods have proved acceptable to patients. We have attempted to convey the impression that they are receiving new treatment, and this appears to have encouraged regularity of drug intake to an extent that would have been hard to achieve had the patient merely continued on treatment with a tablet with which he was already familiar and possibly dissatisfied.

The problems of such a trial in the context of a leprosy control programme are primarily administrative. A special group of patients must be recognized and receive special management. Additional documentation and medication may be needed, and measures should be taken to ensure that patients can be observed regularly over a long period. There is, however, one esential addition to training programmes. It must be taught that for the early diagnosis of dapsone resistance, smears should be taken from active lesions, not only from "standard sites". It is unusual for patients with dapsone resistance to show a gradual rise in BI at standard skin smear sites. Much more commonly there is a sudden jump from negative or almost negative to $4+$ or $5+$, when smears are taken from a small number of new active lesions. These lesions can only be seen if the patient is undressed and examined. Smears taken under any other conditions will give a false sense of security, and staff taking smears must be taught the need for care in selecting smear sites in potentially dapsone-resistant cases.

Urine tests for the presence of dapsone (Low and Pearson, 1974) are technically straightforward and inexpensive in materials. However, they require apparatus (a spectrophotometer) which is normally available only in central laboratories; they also require supervision and monitoring for quality control. The main problems of their use, however, are the obtaining in rural clinics of specimens from female patients, and the logistics of transportation of urine specimens from remote clinics to the central laboratory. If these problems can be solved, these tests can of fer invaluable evidence of regularity of dapsone intake.

Two additional facilities can be of value in the proof of dapsone-resistant leprosy.

(a) Skin biopsies can be of value in assessing the progress and activity of the disease, and occasionally in the diagnosis of atypical reactions. But they are inconvenient for staff and patients, and require good quality processing and skilled interpretation, neither of which are always readily available.

(b) Mouse foot-pad tests can be used for independent confirmation of dapsone resistance. But they are not widely available, and give no more information than a well conducted clinical trial. If available, they should be reserved for occasional use to confirm the accuracy of the clinical trial technique, for 
problem cases, and for possible cases of primary dapsone resistance. It is usually better for them to be initiated at the end of the clinical trial rather than the start.

\section{GENERAL IMPLICATIONS OF DAPSONE-RESISTANT LEPROSY FOR LEPROSY CONTROL PROGRAMMES}

For many years dapsone-resistant leprosy has hardly been considered as a problem for leprosy control, because of the small number of reported cases. There is now, however, good evidence that every year in the Addis Ababa area about 3\% of lepromatous cases under treatment develop symptoms suggestive of dapsone resistance. There is also evidence, both documented and particularly anecdotal that this figure may not be atypical for other parts of the world. This high incidence must greatly influence the planning and execution of leprosy control programmes in the near future, though the final aim (reduction of the incidence of leprosy) and general methods (early detection and regular treatment of all cases for sufficiently long) will remain unchanged.

The low cost, low toxicity, and high "safety margin" of dapsone make it outstandingly the most suitable and widely used drug for the large scale treatment of leprosy by relatively unskilled personnel. Leprosy control in a situation where dapsone is ineffective is almost literally unthinkable. Leprosy control programmes must therefore have, as one of their aims, "the prevention of primary dapsone-resistant leprosy". This aim, in turn, may be divided into 2 components: "the prevention of acquired dapsone resistance" (affecting chiefly therapeutic policies and budgeting); and "the early diagnosis of dapsone-resistant leprosy" (affecting chiefly staff training, supervision and administration). In addition, once dapsone-resistant leprosy has been diagnosed it must be correctly treated. Supervision will be required, particularly for the organizational aspects of the diagnosis and treatment of dapsone-resistant leprosy. And finally, a high incidence of dapsone-resistant leprosy has implications for the integration of leprosy within general medical services.

\section{The prevention of acquired dapsone-resistant leprosy}

The principles of prevention of drug resistance are well known and have been proved in the chemotherapy of tuberculosis. If 2 drugs with different modes of action are employed together, the bacilli resistant to one will be killed by the other. In leprosy, however, the unusual "safety margin" of dapsone may make it necessary to employ multiple drug therapy only for an initial period of intensive treatment, monotherapy with dapsone sufficing thereafter.

The implications of multiple drug therapy are primarily financial; the "second line" drugs for leprosy (thiacetazone, streptomycin, clofazimine, rifampicin and ethionamide) are more expensive, generally by a factor of 100 or so, than dapsone. The necessity for their use will present a challenge to budgeting for leprosy control.

There are, however, other implications, for training and for organization.

(a) Training. Health workers and supervisors will need to be taught how to handle drugs with a much lower "safety margin" than dapsone. They must be aware of the symptoms of toxicity; and also aware that the drug combinations they use are novel and may have unpredictable toxic effects.

(b) Organization. Because little is known of the relative effectiveness or the 
toxicity of any of the multiple drug regimens that must soon be introduced into leprosy chemotherapy, each programme must be regarded as experimental. This means that closer than average supervision will be required, to assess effectiveness, to determine cost-effectiveness, and to document toxicity (which may well vary in different parts of the world). Clinical documentation may require modification if these requirements are to be fulfilled, and the additional responsibilities will increase the burden of leprosy supervisors.

\section{The diagnosis and management of suspected dapsone-resistant leprosy}

Patients with acquired dapsone-resistant leprosy are all lepromatous, and therefore potentially infectious. There is little difficulty in the diagnosis of advanced cases; but early diagnosis is required to prevent the spread of dapsone-resistant bacilli. To achieve this is more a matter of training and organization than of money.

(a) The training syllabus of health workers must include the history and signs of dapsone-resistant leprosy, and how to differentiate it from reactions.

(b) There must be provision in leprosy clinics for regular (at least annual) examination (disrobed, in adequate light) of all patients under treatment for lepromatous leprosy. When patients show signs that are suspicious of dapsone resistance, careful clinical drawings must be performed, and good quality skin smears taken from active lesions. This might be the responsibility of health worker or supervisor, according to circumstances; it will probably require specif ic documentation.

(c) Alternative forms of dapsone for a period of trial treatment must be available. These should be reserved for patients with suspected dapsone resistance, and probably issued to field workers in accurate quantities for specific patients.

(d) There must be a registration system for these patients, to ensure that serial clinical assessments and skin smears are performed at least 6-monthly, and that special dapsone treatment is available for them in their clinics.

(e) If urine dapsone tests are available, arrangements for collection and transportation of specimens, and recording of results are required.

\section{The treatment of proven dapsone-resistant leprosy}

The proof of dapsone resistance is failure to respond to supervised dapsone treatment. The trial period must be as short as possible, to prevent both damage to the patient and spread of dapsone-resistant $M$. leprae. Nevertheless the trial must be long enough to ensure that the diagnosis is accurate. Corect diagnosis is important for both the patient and the control programme. For the patient, because the second line drugs he must take are likely to be less effective and have more side effects than dapsone; and for the control programme, because the cost of drugs to treat this one patient will be comparable to that of dapsone to cure 1000 patients with tuberculoid leprosy.

The decision that a patient has dapsone-resistant leprosy is important clinically and administratively, and should therefore be the responsibility of a senior supervisor or doctor. Once the decision has been made, arrangements will be required for the patient to be supplied with the second line drugs he will need in his own clinic. 


\section{Supervision of the programme}

The efficient performance of a programme for the management of dapsoneresistant leprosy is most likely to be achieved if it is the responsibility of a single person, either a doctor or senior supervisor. His areas of concern will include clinical work, teaching, supervision, and administration, though their proportions will vary greatly in different control programmes, and some responsibilities will be delegated.

(a) Clinical work and teaching

1. Teach leprosy staff and others concerned the history, clinical features, and differential diagnosis of dapsone-resistant leprosy.

2. Ensure that staff can take skin smears and perform clinical assessments of leprosy patients.

3. Teach staff the indications, dosage, and toxic effects of "second line" anti-leprosy drugs.

4. Teach staff how to conduct the clinical trial to confirm the diagnosis of dapsone-resistance in suspected cases.

5. Arrange for proven cases to be transferred to new treatment, and do so himself if authorized.

6. Undertake the activities he teaches, both on field trips and for patients referred to hospital.

(b) Supervision and administration

1. Maintain a register of suspected and proven cases of dapsone-resistant leprosy.

2. Ensure that registered patients are assessed regularly, that results of their assessments are recorded in the central registry, and that their medicines are available in their clinics.

3. Assess the accuracy of diagnosis by monitoring assessments and results of tests, and by field visits.

4. Ensure quality control of skin smears (their taking, staining, and counting) and of urine dapsone tests, if undertaken.

5. Organize for mouse foot-pad tests to be performed in sample patients and in problem cases.

It should be noted that these activities, conscientiously performed, are likely to upgrade the whole of a leprosy control programme. For instance, skin smears are usually inadequately performed, and few workers know how to assess the clinical progress of patients; these skills will be of value for other than dapsone-resistant cases. Also the general use of second line drugs in leprosy clinics is inevitable, and while it will increase the demands on leprosy workers, it may also increase their interest and job satisfaction, and so improve the general quality of patient care.

The training of such a supervisor should be sufficient to enable him to perform competently the tasks he must teach and supervise. For the clinical and technical aspects it will be necessary for him to work in a unit which is regularly involved in the management of patients with dapsone-resistant leprosy; a period of attachment of about a month will be needed even by an experienced supervisor. It will be important for his responsibilities to be precisely defined, particularly in administrative matters, where his programme should complement existing activities. 


\section{Implications for integration}

The treatment of leprosy has never been merely the issue of dapsone tablets, and leprosy control involves far more than leprosy treatment. Nevertheless, in the past the simplicity and safety of treating uncomplicated leprosy provided a strong argument for the complete integration of leprosy programmes into general medical services. The benefit to patients of being able to obtain treatment at a non-specialized clinic, and so avoiding stigmatization, was also considerable in some parts of the world. The question, "Why, in the circumstances, did most leprosy control programmes remain specialized?" may best be answered by another question, "Why did so many integrated programmes fail to control leprosy?".

The demonstration that dapsone-resistant leprosy is now a significant problem for leprosy control greatly increases the responsibilities and problems of those treating leprosy. Incorrect large scale treatment (that is, monotherapy with dapsone) will certainly worsen the problem, possibly to the extent that dapsone could become almost valueless. Were this to happen, it is doubtful if leprosy control could ever be achieved by chemotherapy. On the other hand, what is "correct" therapy is still not known, and the problem can only be solved by large scale trials which can only be conducted by specialized programmes. For at least 5 or 10 years, till more answers are known to what are now chemotherapeutic problems, there appears to be a strong case for retaining and upgrading leprosy control as a specialized service. It is possible that such a service would be better able to undertake treatment of other diseases; but the ill-advised integration of leprosy services into general medical programmes now will seriously damage the prospects for leprosy control in the future.

\section{Acknowledgements}

We are grateful to staff members of the National Leprosy Control Project and of the All Africa Leprosy and Rehabilitation Training Centre (ALERT) who referred patients for assessment and contributed to their clinical management. The Armauer Hansen Research Institute (AHRI) supplied animal house and other facilities for the mouse foot-pad tests performed in Ethiopia. One of us (G. S. H.) was supported by Medical Research Council Project grant G.975/171.

\section{References}

Garrod, J. M. B. and Ellard, G. A. (1968). Appearance of resistance during prolonged treatment of leprosy with thiambutosine. Lepr. Rev. 39, 113.

Hastings, R. C., Trautman, J. R. and Mansfield, R. E. (1969). Further observations on streptomycin combined with sulphones in relapsed lepromatous leprosy Int. J. Lepr. 37, 130.

Low, S. J. M. and Pearson J. M. H. (1974). Do leprosy patients take dapsone regularly? Lepr. Rev. 45, 218.

Pearson, J. M. H., Pettit, J. H. S. and Rees, R. J. W. (1968). Studies on sulphone resistance in leprosy. 3. A case of "partial" resistance. Int. J. Lepr. 36, 171.

Pearson, J. M. H., Haile, G. S. and Rees, R. J. W. (1977). Primary dapsone-resistant leprosy. Lepr. Rev. 48, 000.

Pearson, J. M. H., Rees, R. J. W. and Waters, M. F. R. (1975). Sulphone resistance in leprosy. A review of 100 proven clinical cases. Lancet ii, 69 .

Pettir, J. H. S. and Rees, R. J. W. (1964). Sulphone resistance in leprosy. An experimental and clinical study. Lancet ii, 673. 
Shepard, C. C., Levy, L. and Fasal, P. (1969). The sensitivity to dapsone (DDS) of Mycobacterium leprae from patients with and without previous treatment. Amer. J. Trop. Med. Hyg. 18, 258.

Waters, M. F. R., Rees, R. J. W. and Ellard, G. A. (1968). Experimental and clinical studies on the minimal inhibitory concentration (MIC) of dapsone (DDS) in leprosy. Int. J. Lepr. 36,651 . 